\section{GEMINI: \\ Program for analysis of structural equations with standard errors of indirect effects}

\author{
LEE M. WOLFLE \\ Virginia Polytechnic Institute and State University, \\ Blacksburg, Virginia \\ and \\ CORINNA A. ETHINGTON \\ University of Illinois at Chicago, Chicago, Illinois
}

GEMINI is a main-frame computer program, written in FORTRAN77, that analyzes recursive structural equation models and provides standard errors of all direct and indirect effects. From the input of a correlation matrix, means, standard deviations, and a few control cards defining the equations in the model, the program estimates all of the equations in the model with a multiple regression routine. The program then calculates all of the total indirect effects implied by the model, and calculates their large-sample asymptotic standard errors with a method developed by Sobel (1982).

Introduction to Structural Equation Analysis. Causal modeling originated with the work of the statistical geneticist Sewall Wright $(1921,1934)$, and was introduced to the social sciences by Blalock (1964) and Duncan (1966). Introductions to the methodology are available in Duncan (1975) and Kenny (1979), and reviews of applications can be found in Bielby and Hauser (1977), Goldberger (1972), and Wolfle (1985).

An attractive feature of causal models is the ability to decompose zero-order measures of association into a sum of simple and compound paths, some of which are interpretable as direct causal effects and some as indirect causal effects. Direct causal effects in recursive causal models are estimated by partial regression coefficients. Indirect causal effects are estimated by the sum of products of direct causal effects through intervening variables. These decompositions provide a basis for substantively interpreting the causal effects that some variables have on other variables in a causal model. These coefficients, both direct and indirect, can be expressed in either standardized or unstandardized (metric) form; generally, however, the unstandardized coefficients convey more substantive meaning and are preferred for that advantage (Duncan, 1975; Kim \& Mueller, 1976).

\footnotetext{
A portion of this work was completed while the first author was a Visiting Fellow at Educational Testing Service; their support is gratefully acknowledged. L. M. Wolfle's mailing address is: College of Education, University City Office Building, Virginia Polytechnic Institute and State University, Blacksburg, VA 24061.
}

Indirect Effects. Much has been written about how to estimate and interpret indirect causal effects in structural equation models. Early introductions to path analysis (e.g., Duncan, 1966; Land, 1969) confused noncausal components with indirect effects, but Finney (1972), among others, corrected this misinterpretation. Early methods for decomposing causal effects involved "reading" path diagrams or algebraically decomposing zeroorder correlations using the fundamental theorem of path analysis (see Duncan, 1966; Wolfle, 1980), but computerized methods soon began to appear. Alwin and Hauser (1975) showed for just-identified recursive models that reduced-form equations could be used to estimate total effects. Indirect effects then could be obtained by subtracting the appropriate final-equation coefficients from their respective coefficients in the reduced-form equation. Wolfle (1982) provided a microcomputer program that calculates all direct and indirect effects in recursive causal models utilizing this method.

Fox (1980) introduced a more efficient and general technique for calculating indirect effects that involved raising a matrix of direct effects to successive powers, until a zero matrix was obtained, and summing the results. Joreskog and Sorbom (1983, p. III.39) provided a more general procedure that holds for models with or without latent variables, for recursive or nonrecursive models, and for just-identified or overidentified models. Graff and Schmidt (1982) showed how the LISREL decompositions can be applied usefully to evaluation studies of unintended consequences of social programs.

Standard Errors of Indirect Effects. Despite the enormous interest in estimating indirect causal effects, their probability distribution was unknown for a long time. Thus, most users of causal modeling techniques treated estimates of indirect effects as if they were population parameters and did not test whether they were statistically significant. Testing the significance of indirect effects began when Sobel (1982) derived the asymptotic distribution of indirect effects in recursive causal models. Sobel used the delta method (Rao, 1973) to show that the large sample variance/covariance matrix for total indirect effects may be approximated by:

$$
(\partial \mathrm{F} / \partial \delta)[\Sigma(\delta)]^{-1}(\partial \mathrm{F} / \partial \delta)^{\prime},
$$

where $F$ is a vector of estimated indirect effects, $\delta$ is a vector of estimated direct effects, and $\Sigma(\delta)$ is the variance/covariance matrix for the estimates in $\delta$. (For a complete account of the derivation of the equation shown above, consult Sobel, 1982.)

Following the work of Sobel (1982), Wolfle and Ethington $(1984,1985)$ developed an algorithm for calculating partial derivatives of indirect effects with respect to their direct-effect components, and incorporated this algorithm into a FORTRAN program called SEINE that made the 
calculation of standard errors in recursive causal models a relatively easy task, although the program input could get tedious for large models. Recently, Sobel (1984) has extended his work to include standard errors for indirect effects in causal models featuring latent variables, nonrecursive causal effects, and equality constraints among structural effects; Stone (1985) has provided a new computer program incorporating these advances.

The GEMINI Program. GEMINI requires the input of a title card; a card that includes the number of variables to be input, the number of endogenous variables, and the number of cases in the sample; labels for the variables to be input; a card that specifies whether a full or lower diagonal correlation matrix is to be read; the correlation matrix; a vector of means; a vector of standard deviations; a series of model specification cards, which include the index number of the dependent variable, the number of independent variables, and the index numbers of the independent variables, for each equation in the model; and an order/select card, which specifies the causal order of the variables in the model from right to left as causal models are usually presented diagrammatically.

With these data and instructions, the program calculates each regression equation as specified, and stores the direct effects and their variances and covariances for subsequent analysis. Once all of the equations have been estimated, the indirect effects are calculated using Fox's (1980) algorithm of raising the matrix of structural parameter estimates to successive powers and summing the results, thus obtaining a matrix of total indirect effects. The program next calculates the partial derivative of each indirect effect with respect to each direct effect. The standard errors of indirect effects are obtained by taking the square roots of the diagonal elements of the matrix shown in Equation 1.

The output provided by the program begins with an echo printing of the control cards as interpreted by GEMINI. The program next reprints the means, standard deviations, number of cases, and the correlation matrix. For each equation in the model, the program next prints the regression estimates, including the multiple correlation coefficient, the coefficient of determination or $\mathrm{R}^{2}$, the standard error of estimate, the ANOVA table for the regression, the unstandardized regression coefficients and their standard errors, the standardized regression coefficients or beta weights, the $t$ ratios for the regression coefficients, and the probabilities of the $t$ ratios.

The program next prints, in summary form, a matrix of direct effects, the matrix of unstandardized indirect effects and their standard errors, the matrix of associated $t$ ratios, and finally a matrix of probabilities for the $t$ ratios. (If standardized indirect effects are desired, one need only include a vector of zero means and unit standard deviations in the program setup.)

An Example. This example is taken from Duncan (1966). Based on an earlier analysis by Duncan and Hodge (1963), Duncan (1966) analyzed the longitudinal process of occupational careers as influenced by socioeconomic origins. He lacked a real cohort of United States men whose experiences had been traced over time, but was able to estimate his model with a synthetic cohort using data from Duncan and Hodge (1963). The analysis of these data suggested that the early stages of a man's career depend upon socioeconomic background factors (father's occupational status and respondent's education). After the age of 35-44, however, the direct effects of these background variables become negligible, although respondent's education maintains at all ages a degree of importance greater than that of father's occupation. Compensating for the declining influence of social background is an increasing stabilization of occupational status after age 35-44.

Thus, United States men from advantaged families tend to enter occupations of higher status, and because occupations tend to stabilize over the course of a lifetime, tend to maintain their higher occupational standing. The question to be addressed here is whether the indirect effects of socioeconomic origins are statistically significant causes of occupational status at older ages; that is, by the time a man has reached the age of 55-64, do his status origins continue to have an influence on his status through his intervening occupational achievements, or, like the direct effects of social background, do they become negligible and statistically insignificant over time? To answer these questions, the statistical significance of the indirect structural effects implied by Duncan's (1966) model, shown in Figure 1, were determined. Using an estimated sample size of 1,105 , which was the number of respondents in Duncan and Hodge's (1963) analysis, the model was estimated with GEMINI.

To illustrate how data and control cards are input into GEMINI, the control cards are reproduced here:

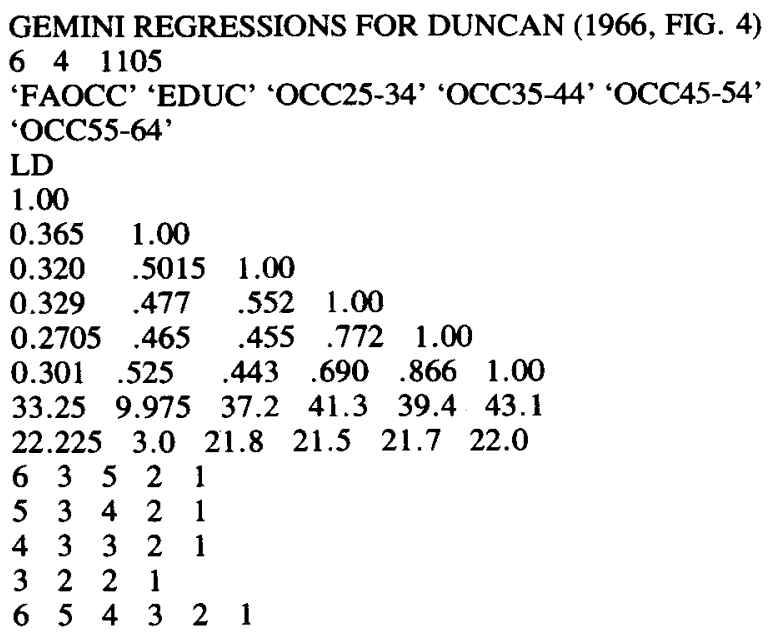

The first line of the program contains the title. The second card indicates that there are six variables in the model, four of which are endogenous, and that the sam- 


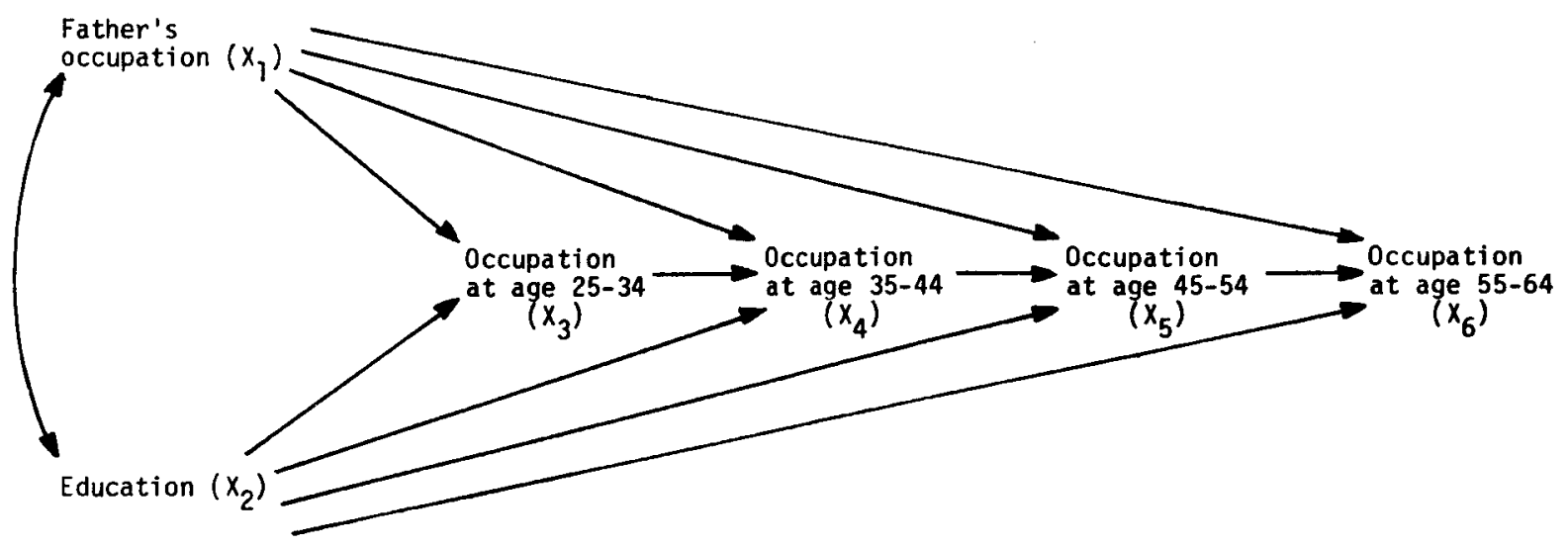

Figure 1. Respondent's occupational status at successive ages in relation to father's occupational status and respondent's educational attainment (based on Duncan, 1966, p. 13).

ple size is 1,105 . The labels follow. GEMINI will read either a full, symmetrical correlation matrix or a lower diagonal matrix. In this case, a lower diagonal correlation matrix is to be read; thus the correlation matrix definition card contains the command LD. The row-wise correlation matrix follows, along with vectors of means and standard deviations. The model definition cards follow, one for each endogenous variable in the model. For example, the first model definition card specifies that $X_{6}$ is caused by three independent variables: $X_{5}, X_{2}$, and $X_{1}$. The last card specifies the order of the variables in the model in reverse causal order, that is, from right to left in Figure 1.

The results of this analysis are summarized in Table 1 . The upper matrix in Table 1 shows the estimated direct effects as implied by the model shown in Figure 1; the standard errors of these estimates are shown in parentheses. The effects from father's occupation on respondent's occupation at age 55-64, and from the same exogenous variable on occupation at age 45-54, were not statistically significant at the .01 level of probability; all other direct effects in the model were significant at that level.

The indirect effects are shown, along with their standard errors, in the bottom half of Table 1 . These coefficients clearly show that all of the indirect effects of education and father's occupation on respondent's occupational prestige are statistically significant at every age. In summary, social origins have strong direct causal effects on occupational status early in life, but their direct influence tends to wane over time. Nevertheless, social origins continue to have strong indirect causal effects throughout life via intervening achieved statuses.

Summary. Researchers employing structural equation techniques have been interested for many years in indirect causal effects. Although rigorous methods for testing hypothesized direct effects in causal models have been employed to assess their statistical significance, indirect effects were treated as if they were population parameters. Following the statistical development described by Sobel (1982), the program described in this paper makes available to the causal-model analyst an easy-to-use program that provides both direct and indirect causal estimates and their standard errors. The standard errors of indirect effects, like the commonly reported standard errors of direct effects, should become a routine part of the presentation of structural equation results.

Availability. GEMINI is available in FORTRAN77 source code along with a user's guide. Please address inquiries to the first author. The cost of providing the program varies. It can be sent via BITNET without charge.

Table 1

Summary of Causal Effects in Duncan's (1966) Model of Occupational Status at Successive Ages

\begin{tabular}{|c|c|c|c|c|}
\hline \multirow{2}{*}{$\begin{array}{l}\text { Predetermined } \\
\text { Variables }\end{array}$} & \multicolumn{4}{|c|}{ Endogenous Variables } \\
\hline & Occ55-65 & Occ45-54 & Occ35-44 & Occ25-34 \\
\hline \multicolumn{5}{|l|}{ Direct Effects } \\
\hline Occ45-54 & $\begin{array}{l}.800 \\
(.017)\end{array}$ & & & \\
\hline Occ35-44 & - & $\begin{array}{l}.721 \\
(.022)\end{array}$ & & \\
\hline Occ25-34 & 一 & - & $\begin{array}{l}.391 \\
(.028)\end{array}$ & \\
\hline Education & $\begin{array}{l}1.067 \\
(.125)\end{array}$ & $\begin{array}{l}.928 \\
(.160)\end{array}$ & $\begin{array}{l}1.689 \\
(.205)\end{array}$ & $\begin{array}{l}3.225 \\
(.200)\end{array}$ \\
\hline FathOcc & $\begin{array}{l}.034 \\
(.015)\end{array}$ & $\begin{array}{l}-.011 \\
(.020)\end{array}$ & $\begin{array}{l}.122 \\
(.025)\end{array}$ & $\begin{array}{l}.155 \\
(.027)\end{array}$ \\
\hline \multicolumn{5}{|l|}{ Indirect Effects } \\
\hline Occ35-44 & $\begin{array}{l}.577 \\
(.021)\end{array}$ & & & \\
\hline $0 \operatorname{cc} 25-34$ & $\begin{array}{l}.226 \\
(.018)\end{array}$ & $\begin{array}{l}.282 \\
(.022)\end{array}$ & & \\
\hline Education & $\begin{array}{l}2.445 \\
(.172)\end{array}$ & $\begin{array}{l}2.128 \\
(.158)\end{array}$ & $\begin{array}{l}1.262 \\
(.119)\end{array}$ & \\
\hline FathOcc & $\begin{array}{l}.091 \\
(.022)\end{array}$ & $\begin{array}{l}.125 \\
(.020)\end{array}$ & $\begin{array}{l}.061 \\
(.011)\end{array}$ & \\
\hline
\end{tabular}

Note-Standard errors are in parentheses. 
The program will be copied onto your IBM-PC floppy disk without charge; we can supply the disk for $\$ 3$. The program will be copied onto your magnetic tape at a charge of $\$ 5$; we will supply the tape for $\$ 15$. In all cases, please submit $\$ 10.00$ for handling, postage, and duplication of the GEMINI User's Guide.

\section{REFERENCES}

Alwin, D. F., \& Hauser, R. M. (1975). The decomposition of effects in path analysis. American Sociological Review, 40, 37-47.

BiELBY, W. T., \& HAUSER, R. M. (1977). Structural equation models. In A. Inkeles (Ed.), Annual Review of Sociology. Palo Alto: Annual Reviews, Inc.

BLALOCK, H. M., JR. (1964). Causal inferences in nonexperimental research. Chapel Hill: University of North Carolina Press.

Duncan, O. D. (1966). Path analysis: Sociological examples. American Journal of Sociology, 72, 1-16.

DunCaN, O. D. (1975). Introduction to structural equation models. New York: Academic Press.

DunCAN, O. D., \& HoDge, R. W. (1963). Education and occupational mobility: A regression analysis. American Journal of Sociology, 68 , 629-644.

FiNNEY, J. M. (1972). Indirect effects in path analysis. Sociological Methods \& Research, 1, 175-186.

Fox, J. (1980). Effect analysis in structural equation models: Extensions and simplified methods of computation. Sociological Methods \& Research, 9, 3-28.

GoldBERGER, A. S. (1972). Structural equation methods in the social sciences. Econometrica, 40, 979-1001.

GRAFF, J., \& SCHMIDT, P. (1982). A general model for decomposition of effects. In K. G. Joreskog \& H. Wold (Eds.), Systems under indirect observation: Causality, structure, prediction. Amsterdam: North-Holland.

JoResKoG, K. G., \& SORBOM, D. (1983). LISREL VI: Analysis of linear structural relationships by maximum likelihood and least squares methods. Chicago: National Educational Resources.
KENNY, D. A. (1979). Correlation and causality. New York: Wiley. KIM, J., \& MUELLER, C. W. (1976). Standardized and unstandardized coefficients in causal analysis: An expository note. Sociological Methods \& Research, 4, 423-438.

LAND, K. C. (1969). Principles of path analysis. In E. F. Borgatta (Ed.), Sociological methodology 1969. San Francisco: Jossey-Bass.

RAO, C. R. (1973). Linear statistical inference and its applications. New York: Wiley.

SoBEL, M. E. (1982). Asymptotic confidence intervals for indirect effects in structural equation models. In S. Leinhardt (Ed.), Sociological methodology 1982. San Francisco: Jossey-Bass.

SOBEL, M. E. (1984). Some new results on indirect effects and their standard errors in covariance structure models. Unpublished manuscript, Department of Sociology, University of Arizona, Tucson.

STONE, C. A. (1985, April). CINDESE: Computing indirect effects and standard errors in the Joreskog covariance structure model. Paper presented at the annual meeting of the American Educational Research Association, Chicago, Illinois.

Wolfle, L. M. (1980). Strategies of path analysis. American Educational Research Journal, 17, 183-209.

Wolfle, L. M. (1982). PASE: Program for analysis of structural equations. Behavior Research Methods \& Instrumentation, 14, 548-550.

Wolfle, L. M. (1985). Applications of causal models in higher education. In J. C. Smart (Ed.) Higher education: Handbook of theory and research, Volume $I$. New York: Agathon Press.

Wolfle, L. M., \& EThington, C. A. (1984, April). A program for standard errors of indirect effects in recursive causal models. Paper presented at the annual meeting of the American Educational Research Association, New Orleans, Louisiana.

Wolfle, L. M., \& Ethington, C. A. (1985). SEINE: Standard errors of indirect effects. Educational \& Psychological Measurement, 45, 161-166.

WRIGHT, S. (1921). Correlation and causation. Journal of Agricultural Research, 20, 557-585.

WRIGHT, S. (1934). The method of path coefficients. Annals of Mathematical Statistics, 5, 161-215.

(Revision accepted for publication October 22, 1985.) 